\title{
Successes and Challenges in Industrial Clusters: Some Empirical Evidence from Wood Industrial Cluster in Kumasi, Ghana
}

\author{
Martin Amoah ${ }^{1}$, Gbapenuo Enoch $^{2}$, Peter Kessels Dadzie ${ }^{3,}$, Joseph Asomani ${ }^{4}$ \\ ${ }^{1}$ Faculty of Technical Education, University of Education Winneba, Kumasi, Ghana \\ ${ }^{2}$ Department of Construction and Wood Technology, University of Education Winneba, Kumasi, Ghana \\ ${ }^{3}$ Interior Design and Materials Technology Department, Kumasi Technical University, Kumasi, Ghana \\ ${ }^{4}$ Department of Construction and Wood Technology, University of Education, Winneba, Ghana
}

\section{Email address:}

martamoah@yahoo.com (M. Amoah), akwasiamponsah07@gmail.com (M. Amoah), pkkdadzie@yahoo.com (P. K. Dadzie), peter.kdadzie@kpoly.edu.gh (P. K. Dadzie)

${ }^{*}$ Corresponding author

\section{To cite this article:}

Martin Amoah, Gbapenuo Enoch, Peter Kessels Dadzie, Joseph Asomani. Successes and Challenges in Industrial Clusters: Some Empirical Evidence from Wood Industrial Cluster in Kumasi, Ghana. Journal of Investment and Management. Vol. 7, No. 1, 2018, pp. 1-12. doi: $10.11648 /$ j.jim.20180701.11

Received: October 22, 2017; Accepted: November 21, 2017; Published: March 5, 2018

\begin{abstract}
This study examined some successes and challenges of a wood cluster in Kumasi, Ghana. A concurrent mixed method comprising survey, regression analysis, and correlation analysis were adopted to probe into how the effects of interconnections among firms in the cluster, the successes chalked and the challenges firms face in the cluster. Results showed significant $(\mathrm{p}<0.001)$ interconnections among actors contributed to significant increase in productivity, sales and profit margins of the firms. Majority (93.4\%) of respondents affirmed appreciable increases in sales and profit margins demonstrating that the cluster has been a major driver of economic growth. Permanent site for the artisans and other actors was the major benefit, provided by the cluster. However, lack of access to bank loans, timber, and waste management facility, promoting and marketing of products are some challenges associated with the cluster. Interventions from government and other agencies are required to create the enabling environment to attract investors that can help in addressing the challenges so as to stimulate growth of the wood and furniture enterprises in the cluster as they have greater potential for Ghana's economic development.
\end{abstract}

Keywords: Industrial Clusters, Wood Artisans, Sokoban Wood Village, SMEs in Ghana

\section{Introduction}

Industrial clustering geographically concentrates interconnected companies, specialized suppliers, service providers, firms in related industries, and associated institutions such as universities, standards agencies, trade associations, in a particular field to compete but also cooperate for mutual benefits, growth and development [1]. Industrial clusters have played different roles in nations' economic development including being the main drivers of innovation, business retention and expansion, financial incentives to firms, entrepreneurship and commercial research [2]. They have therefore become popular strategy for rural economic development for several years, yet their holistic contributions to countries with growing economies such as Ghana have not been fully examined. In the literature, it is pretty recognised that creativity is frequently characterized by the agglomeration of firms [3]. There is an implicit and confirmed report therefore that such growth translates into rising levels of employment and incomes, with improved conditions and standards for the labour force engaged in clustered industries [4]. It is also documented that industrial clusters result in easy access to suppliers and customized support services, creation of framework for firms to collaborate with one another and governments to promote common interests, and develop specialized labour pools. All of these are precursors to improved conditions and labour 
efficiency standards which in turn provide the needed capacity to position companies for favourable competition in the global markets [2]. It follows therefore that industrial clusters promote sustainable employment and incomes generation, and can also better the economic situations of the working population and nations as a whole especially those with crawling economies. In relation to this, it is reported that in Ghana, clustered and unclustered SMEs employ about $60 \%$ of the workforce [5], and one of the clustered entities is the Sokoban Wood Industrial Cluster (SWIC), popularly called 'Sokoban Wood Village (SWV)'.

However, it appears that there is scarce published evidence regarding the opportunities and challenges of the SWIC investment in Ghana and its socio-economic impact on the livelihoods of the artisans as well as the other actors who contribute to the business activities in a cluster especially in relation to wood industries in Ghana. It is for this reason that this study was conducted to assess the interrelationships and benefits of actors in the SWIC in Ghana and to offer suggestions that could sensitize and encourage stakeholders to support the artisans to do better for national development. The purpose of this study was therefore threefold; first, was to examine the interrelationships among actors in the cluster. Second, was to assess the impact or benefits that clustering has provided to artisans and other actors. Finally, it was to highlight the challenges that artisans encounter and offer appropriate recommendations to address them. The findings in this study are expected to encourage firms in the cluster to continue to be together while making known what clustering offers to firms so as to entice firms in other industries to form clusters.

\section{Literature Review}

Due to the social and economic benefits of clusters, there has been growing interest in industrial clusters as a concept and instrument for influencing rural renewal which has seen some attention among policy makers of industrial and postindustrial nations [6]. As a result, many planners and community developers have been striving to improve the economic fortunes of their localities by developing new and rejuvenating existing industrial clusters $[7,8]$. It is reported that European countries in the 1990s therefore undertook substantial experiments in the use of business networking schemes as a mechanism for encouraging collaborative competition and learning economies among small firms towards growth and development $[9,10]$. This is exemplified in the US, UK, France, Germany, Brazil, India and other countries where local and national authorities have recognized industrial clusters as important for industrial modernization and wealth creation [11, 12, and 13]. In like manner, [14] outlined that countries such as the Netherlands, Austria, Denmark, and Finland have established cluster initiatives that have been more sustained and of somewhat greater sophistication in the world. Clustering of industries is therefore widely considered as a means of addressing the wide disparity in economic conditions as between developed and the developing countries across the world [15].

Apparently, reports indicate that enterprises in clusters seem to grow faster and generate more profits than those outside cluster and therefore operate in isolation or dispersed manner. Such manifestations are more pronounced in developing countries [16]. Among the reasons ascribed for this is that small manufacturing enterprises in developing countries are either more geographically dispersed mainly in rural areas and characterized by small firms whose growth prospects and developments largely depend on artisans or consist of clusters of small and micro enterprises that are mainly sited in urban and sub-urban areas due to technology and skills deficiencies confronting the rural areas [17]. As a result, countries which are moving at a snail pace in terms of economic growth and development resort to direct assistance in the form of finance, technology and skills upgrading in creating and promoting the growth of their SMEs. However, the envisaged growth and graduation of these enterprises to medium and large scale ones appear to have faltered [18] possibly because, most of them operates in isolation or dispersed manner from each other which makes it difficult for them to have greater access to some ingredients such as easy communication with suppliers and support services, labour pools, better financial credits and government's supports needed for the expected expansion and growth [19]. Meanwhile, such transition of the SMEs to large scale enterprises is paramount if enterprises are to make meaningful and significant contribution towards the economic growth and development of developing countries. Moreover, for growth and transition to be effective, SMEs must be self-sustaining through technological innovations and building of competitive advantages and industrial networking [2]. It is reported that small manufacturing enterprises which usually cluster together in urban centres usually have the potential to gain from local and external governments, as well as from collective efforts in areas such as comprehensive worker training programmes, supportive relationships with universities for new technologies all of which promotes flexible knowledge and information transfer for specialization about everything from markets to industrial processes to promote growth [8, 19 and 20]. These joint and collaborative actions would therefore enable small enterprises to gain enhancement in their operations with benefits accruing from improved production methods and enhanced capacity. As a result, such co-operations are widely viewed by both the public and corporate bodies in the developed world as a key feature of international competitiveness, growth and development of enterprises [2].

Notwithstanding the foregoing, it is also reported that economic growth is much facilitated by clustering industries due to product specialization, rapid production of specialized products, pooling of skilled labour, as well as the emergence of suppliers, service providers, marketing agents, formation of associations for specific services and healthy lobbying $[1,21]$. Thus, it is beneficial to merge small firms in cities to facilitate the promotion and development of requisite technologies needed for their economic growth and development. Some of such firms 
are the small and medium-scale furniture enterprises (SMFEs). In Ghana such SMFEs contribute substantially to the economic lives of individual artisans and the country at large. Hence, it appears that agglomerating such furniture firms into clusters for improved efficiency and product standards to meet international requirements could be a driving force for much wealth creation in Ghana especially through exports of goods. It follows then that, given the necessary attention, incentives and supports, enterprises in this category could offer avenues for employment to help alleviate poverty and also generate tax revenues towards improved economic lives of people and the nation [22]. In the light of these, governments in Ghana in their industrialization agenda towards attaining middle income status made efforts at exploring how collective efficiency among SMFEs could facilitate their growth and transition to larger enterprises especially in Kumasi where a good number of woodworkers and furniture producers are found. This agglomeration step was also to encourage stakeholders to move away from targeting assistance to individual firms and rather move towards providing support to cluster of enterprises for greater growth and sustainability [23]. It is also important to note that, such joint and collaborative action enhances the capacity and revenues of individual enterprises through access to markets, information, knowledge and other business variables that are crucial for the success of firms, particularly in the creative and high-technology industries [24] such as the wood and furniture ones.

Additionally, it is documented that clusters all over the world have substantially increased the local economic prosperity as well as supplying the needed innovations that drive national, and in some cases global economic growth [25]. Since accelerating economic growth is a key ingredient for creating jobs and meeting poverty reduction targets, industrial clusters formation in Ghana appear to have been noted to have the potential of significantly driving the industrialization agenda of the country towards substantial development that the nation is yearning for. It was based on this that the government of Ghana invested in the establishment of the Sokoban Wood Industrial Cluster (SWIC) some 10 years ago with the aim of bringing together all wood and furniture products related artisans who were hitherto scattered in the Kumasi metropolis as isolated entrepreneurs. The SWIC is basically inhabited by the resettled wood processors from Anloga who supply most wood products required by furniture designers and other wood workers, and consumers within and around the Kumasi metropolis as well as those of other neighbouring countries including Burkina Faso, Mali, Cote d'Ivoire, Benin, just to mention a few. Hence the SWIC has a wider market within Ghana and across the West African sub-region and therefore has the potential for expansion, employment and wealth creation, and subsequently improve the economic lives of the citizenry and the country in general. But such potentials cannot be realized without making the necessary efforts at identifying the challenges and addressing them or identifying opportunities and strengthening them.

Based on the set objectives, this study is expected to have the following research questions and policy implications; first it will explore the question "what are the various issues confronting the SWIC and what mechanisms can be used for harnessing the potential of the SMFEs to effectively contribute to poverty reduction and sustainable forest management in Ghana"? Secondly, it will deal with what coherent policies or strategies could be formulated to assist small and medium-scale enterprises in a cluster and which could serve as a framework within which planning and investment decisions could be made by stakeholders? Finally, the study is also expected to be used as a point of reference for future studies that intend to examine the opportunities and challenges of the SWIC for policy making.

\section{Methods}

\subsection{Study Area}

The study was carried out at the Sokoban Wood Industrial Cluster (SWIC) otherwise referred to as Sokoban Wood Village (SWV) sited in the Kumasi metropolis. Data were collected within a six months period. The area was selected due to its high concentration of wood-based industries in a cluster and its recognizable services to Ghana and across some ECOWAS countries. The cluster is a resettled and upgraded industrial area for groups of wood artisans and other related businesses who were formerly operating in an unclustered manner in the metropolis, particularly at a suburb called Anloga and located along the Asokwa-Ahinsan-Kaase stretch. This stretch also has many of the large scale timber milling and plywood manufacturing firms situated there and therefore providing boots to the operations of the SWIC and the general commercial activities of the area. The SWIC currently has an estimated worker population of 8000 comprising artisans, suppliers, other commercial entities like banks and other petty traders [26]. The cluster/village is therefore a community that houses lumber sellers, carpenters and other woodworkers, with economic activities ranging from the sale of food, wood and wood products to accessories of machines for wood processing banking and other commercial activities that aid easy access to banking and credit facilities [26]. The SWIC is therefore a conglomerated wood industry made up of micro, small, and medium-scale firms owned by private individuals who operate various businesses and produce all kinds of wood products ranging from household furniture to office furniture. As a result, the 'village' has become an industrial cluster of importance to Kumasi city and Ghana as a country. The SWIC is also a wood and wood products producer and supplier to many countries in the West African sub-region. The aforementioned components make the cluster a better place for the researchers to assess the opportunities and challenges that artisans in wood and furniture production business encounter in an industrial cluster environment.

\subsection{Participants}

The participants in this study comprised all the major stakeholders of Sokoban Wood Industrial Cluster (SWIC) 
and included artisans, association executives, and members of wood cluster initiative (WCI). The qualitative part of the study was guided by a case study plan proposed by [27]. Subsequently, through extensive literature search, all the stakeholders were identified and contacted either personally or on telephone. The purpose of the study, issues to be investigated, and why their participation in the study was useful and important were discussed with all participants. Respondents were also given the option to decide on the date, time and place for the interview as the researchers sought to minimize the inconvenience that respondents might be subjected to as a result of their participation. Issues of informed consent, anonymity, confidentiality, and nontraceability proposed by $[27,28]$ for such studies were the guiding principles of this study. Anonymity was further strengthened by the use of pseudonyms for both organization and participants' names. Also, participants were allowed to partake in the interview in a language of their choice but which could be understood by, at least, one of the researchers. This was to allow the respondents to feel comfortable and also to give full account of their feelings, experience, and opinions without being hindered by the English language.

A sample size of three hundred and sixty (360) actors, comprising the artisans, suppliers, buyers and the marketers at the SWIC was targeted for the quantitative study during the field work. Out of this number, three hundredand fifty usable responses were obtained, indicating an impressive response rate of $97.2 \%$. The main reason for targeting this population was that, they constitute a complete set of individuals who have common observable characteristics as the major industrial players, since their livelihoods are directly contoured by the contributions of the wood industry cluster.

\subsection{Instrument for Data Collection}

Concurrent mixed methods were adapted for the study. These methods are reported to have the advantage of increasing the accuracy of the data gathered, thereby providing comprehensive findings as compared to a single approach. Also, [29] asserted that this combined method does not only help to overcome the weakness and biases associated with single approaches, but also aids the researchers to develop analysis and build on the original data. Having analyzed the quantitative data that were collected through the questionnaire, the findings were affirmed when the researchers used interviews to seek qualitative data in order to have profundity of the phenomenon. This allows the informants to tell their own story in their own way, thereby allowing the researchers to have direct access to the experience of the case [30].

Table 1. Measurement scales and assessment of internal consistencies of the major study areas.

\begin{tabular}{|c|c|c|c|c|}
\hline Factors/variables & $\begin{array}{l}\text { Factor } \\
\text { loading }\end{array}$ & $\begin{array}{l}\text { Eigen } \\
\text { value }\end{array}$ & $\begin{array}{l}\text { Cumulated explained } \\
\text { variance }(\%)\end{array}$ & $\begin{array}{l}\text { Cronbach's } \\
\text { alpha }\end{array}$ \\
\hline Interrelationship/Cooperation in information sharing among actors & & 1.725 & 9.35 & 0.72 \\
\hline I share my workshop equipment with members in the cluster & 0.55 & & & \\
\hline I share ideas on new technology with members in the cluster & 0.65 & & & \\
\hline I share information on raw materials with members in the cluster & 0.66 & & & \\
\hline I share information on customers and market conditions with members in the cluster & 0.60 & & & \\
\hline Impact of clustering on product development and marketing issues & & 2.438 & 22.57 & 0.68 \\
\hline In this wood village, we introduce new products & 0.62 & & & \\
\hline In this wood village, we attempt to find new markets & 0.60 & & & \\
\hline In this wood village, we seek to promote and market new products & 0.63 & & & \\
\hline Benefits of industrial cluster & & 1.288 & 5.89 & 0.65 \\
\hline In this village, orders are split among members & 0.67 & & & \\
\hline In this village, we share same technology and labour pool & 0.54 & & & \\
\hline Challenges in the cluster & & 1.296 & 7.83 & 0.71 \\
\hline
\end{tabular}

The questionnaire included (1) demographic data of the respondents (e.g. gender, age, educational level, occupation, number of years in the wood business, location of workshop, number of years at the wood cluster, type of employment and monthly income), (2) impact of the wood cluster on productivity, (3) benefits at the wood cluster and (4) challenges at the wood cluster (Table 1).

Prior to the commencement of the actual survey, five members of SWIC were selected for the pre-test of the questionnaire instrument and such members were excluded from the actual frame. The objective of this was to check all possible ambiguities in the questionnaire items before they were sent to the field for administration. The participants therefore, were requested to assess the content validity, construction, wording and logical arrangement of the questionnaire items. Based on the feedback of the pre-test, some few questions were revised for better understanding.

The internal consistencies of all the measured responses were found to be good (Table 1). For instance, variables of interrelationship or cooperation among actors in terms of information sharing etc. at the SWIC indicated a high internal consistency (Cronbach's Alpha $=0.72$ ). The internal consistency of impact on productivity in terms of product development and marketing issues (Cronbach's Alpha $=0.68$ ), benefits being derived from clustering in terms of work and skilled labour and other resources sharing etc (Cronbach's Alpha $=0.65$ ), and 
challenges in terms of access to credit etc. were all high enough $($ Cronbach's Alpha $=0.71)$.

\subsection{Data Collection}

Data for the study were obtained mainly through the questionnaire, interviews and observations. In the first phase of the study, quantitative data were gathered through the use of a three-part questionnaire with 42 items. After identifying the main actors through extensive literature search, the researchers designed and administered the instruments personally. The researchers visited the SWIC on daily basis, except days of no appointment with any respondent, to administer the instruments. Explanations on the rationale of the study were offered to each respondent while assuring them of confidentiality and anonymity before responses were provided. However, only few of the respondents were able to read and understand the questionnaire items and therefore completed the questionnaire independently. Also, a substantial number of the respondents $(48.9 \%)$ who have not had formal education and therefore could neither read nor write were guided by the researchers to complete the questionnaire without influences their responses. The respondents were given enough time to reflect on the items before they provided their own responses. Qualitative technique was also employed in the final phase of the study through the use of semi-structured interview in order to increase the extensiveness of respondent's characteristics as proposed by [31].

\subsection{Data Analysis}

The quantitative data was analyzed using Statistical
Package for the Social Sciences (SPSS) 16.0 version. Descriptive statistics and frequency analysis were used to evaluate the data obtained. The response with the highest percentage was considered as the general opinion of the respondents with regard to each item. Correlation matrix, Mean (M) and standard deviation (SD) values were also computed for the variables of interest and the total frequency counts were entered. Field notes from the qualitative data were categorized into themes as proposed by [32] which were integrated into the quantitative data in order to validate the findings. Literature search however was extensively used as evidence to support the views collected from the respondents.

\section{Results}

\subsection{Interconnections Among Actors at the Sokoban Wood Industrial Cluster}

The respondents were requested to indicate their activities at the wood cluster by providing multiple responses. A large majority $(82.3 \%)$ were found to be artisans in the cluster. The percentage consisted of skilled craftspersons who are engaged in either apprenticeship, temporal or permanent employment to add value to wood. Others also had dual skills and roles as operators (machinists) as well as repairers of the wood machines in times of breakdowns. It is however, worthy to note that a good number of the artisans who represents a substantial part of the respondents were additionally operating as suppliers (34\%), marketers (20.6\%) and buyers (11.4\%) as ancillary activities which served as supplementary source of income to their main activities.

Table 2. Correlation matrix of the various study variables: $N=78$.

\begin{tabular}{|c|c|c|c|c|c|c|c|c|c|c|c|c|c|}
\hline & SAL & VAD & NPD & FNM & PMP & SWE & SINT & SIM & SICM & ABL & ACF & OSM & STL \\
\hline SAL & 1 & & & & & & & & & & & & \\
\hline VAD & -.04 & 1 & & & & & & & & & & & \\
\hline NPD & .02 & $.35^{\mathrm{a}}$ & 1 & & & & & & & & & & \\
\hline FNM & $.11^{\mathrm{b}}$ & $.23^{\mathrm{a}}$ & $.42^{\mathrm{a}}$ & 1 & & & & & & & & & \\
\hline PMP & -.06 & $.36^{\mathrm{a}}$ & $.32^{\mathrm{a}}$ & $.44^{\mathrm{a}}$ & 1 & & & & & & & & \\
\hline SWE & $.39^{\mathrm{a}}$ & .09 & -.05 & -.01 & .01 & 1 & & & & & & & \\
\hline SINT & $.29^{\mathrm{a}}$ & .07 & .06 & .08 & .02 & $.40^{\mathrm{a}}$ & 1 & & & & & & \\
\hline SIM & $.23^{\mathrm{a}}$ & .07 & $.15^{\mathrm{a}}$ & .02 & $.11^{\mathrm{b}}$ & $.39^{\mathrm{a}}$ & $.43^{\mathrm{a}}$ & 1 & & & & & \\
\hline SICM & $.40^{\mathrm{a}}$ & -.01 & $.12^{\mathrm{b}}$ & .07 & .06 & $.32^{\mathrm{a}}$ & $.44^{\mathrm{a}}$ & $.42^{\mathrm{a}}$ & 1 & & & & \\
\hline $\mathrm{ABL}$ & .07 & .11 & $.16^{\mathrm{b}}$ & $.21^{\mathrm{a}}$ & $.17^{\mathrm{a}}$ & .02 & .04 & -.05 & .07 & 1 & & & \\
\hline ACF & .02 & $.14^{\mathrm{a}}$ & $.23^{\mathrm{a}}$ & $.30^{\mathrm{a}}$ & $.23^{\mathrm{a}}$ & .09 & .09 & .07 & .10 & $.55^{\mathrm{a}}$ & 1 & & \\
\hline OSM & .20 & .02 & .09 & -.04 & .03 & $.18^{\mathrm{a}}$ & $.20^{\mathrm{a}}$ & $.21^{\mathrm{a}}$ & $.25^{\mathrm{a}}$ & -.01 & -.06 & 1 & \\
\hline STL & .10 & .09 & $.13^{\mathrm{b}}$ & $.11^{\mathrm{b}}$ & .07 & $.11^{\mathrm{b}}$ & $.15^{\mathrm{a}}$ & $.12^{\mathrm{b}}$ & $.21^{\mathrm{a}}$ & .05 & .09 & $.38^{\mathrm{a}}$ & 1 \\
\hline
\end{tabular}

$\mathrm{SAL}=$ Sales levels; $\mathrm{VAD}=$ value addition; $\mathrm{NPD}=$ new product development; FNM = finding new markets; PMP = promote and marketing new products; $\mathrm{SWE}=$ share workshop equipment; SINT $=$ share ideas on new technology; SIM $=$ share information on raw material; SICM $=$ share information on customers and market conditions; $\mathrm{ABL}=$ access to bank loan; $\mathrm{ACF}=$ access to credit facilities; $\mathrm{OSM}=$ orders are split among members; $\mathrm{STL}=$ share technology and labour pool

${ }^{\mathrm{a}} \mathrm{p}<0.01 ;{ }^{\mathrm{b}} \mathrm{p}<0.05$

Table 2 shows the Spearman's correlation matrix among the independent variables. Out of 78 correlation coefficients, majority (42) were statistically significant although some were weak. New product development recorded a weak, though significant positive associations with almost all the variables (except for 3 of them), suggesting that the incoherent nature of new product development by wood artisans in the cluster is more likely to hamper the achievements of the projected gains of the wood sub-sector. This may have a rippling effect on the general growth of the Ghanaian economy.

Also from Table 2, promoting and marketing new products exhibited a moderate positive association with new markets $(\mathrm{r}=$ 
$0.44, \mathrm{p}<0.01)$. There was a strong positive association between access to credit facilities and access to bank loan( $\mathrm{r}=0.55, \mathrm{p}<$ 0.01 ), an indication that the availability of bank loans resulting from financial facilities availability and their services is more likely to improve access to credits and a positive ripple effect on the artisans' operations and economic lives. This can be expanded if there is a proliferation of formal and informal credit sources. There was however, a moderate positive association between sharing of ideas on new technology and all other variables; the major ones include the association with sharing information on customers and market conditions ( $\mathrm{r}=0.44, \mathrm{p}<$ $0.01)$, sharing information on raw material $(\mathrm{r}=0.43, \mathrm{p}<0.01)$, and splitting orders among members $(r=0.20, p<0.01)$. These findings indicate that, the firms are significantly involved in joint actions through which they share their limited resources for mutual benefit towards sustainability and development.
Additionally, Table 3 reports the prediction equations for sales and profit margins due to the healthy business interconnection among the actors, and which majority of them recorded significant values $(\mathrm{P}<0.001)$. Considering the $\mathrm{t}$-values, sharing of workshop equipment in relation to sharing information on customers and market conditions $(t=9.130, p<0.001)$ was the highest predictor for sales and profit margins. Sharing ideas on new technology in relation to sharing information on customers and market conditions $(\mathrm{t}=7.700, \mathrm{p}<0.001)$ was the second highest predictor. Other most important predictors obtained included; the share of information on raw materials with respect to customers and market conditions $(\mathrm{t}=7.167, \mathrm{p}<0.001)$, sharing workshop equipment with respect to ideas on new technology $(t=7.339, p<0.001)$ and the share of workshop equipment with respect to information on raw materials $(\mathrm{t}=$ $6.706, \mathrm{p}<0.001)$.

Table 3. Prediction equations for sales and profit margins.

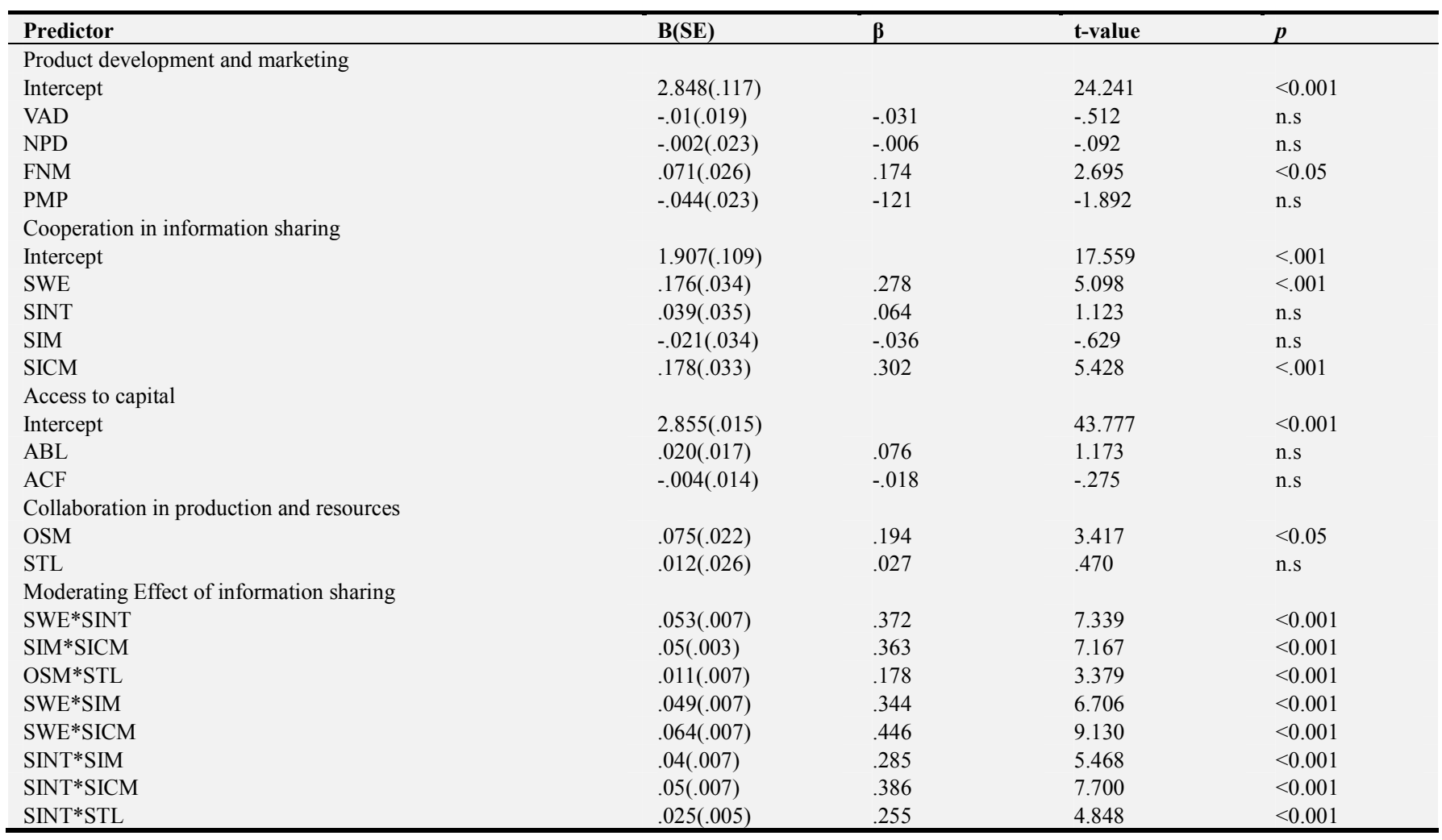

$\mathrm{VAD}=$ value addition; $\mathrm{NPD}=$ new product development; FNM=new markets; $\mathrm{PMP}=$ promote and marketing new products; $\mathrm{SWE}=$ share workshop equipment; $\mathrm{SINT}=$ share ideas on new technology; $\mathrm{SIM}=$ share information on raw material; $\mathrm{SICM}=$ share information on customers and market conditions; $\mathrm{ABL}=$ access to bank loan; $\mathrm{ACF}=$ access to credit facilities; OSM=orders are split among members; STL=share technology and labour pool.

These relationships as presented in Table 3 appear to be good as they point to the facilitation of the diffusion of technology, pooling of skilled workers, and promotion of networking via joint actions which could encourage sales and profit margins and which affirms the realization of economy of scale in the production of furniture and other wood products. Thus these are essential in shaping the productive opportunities of the wood sub-sector.

These findings indicate that, the existing and potential synergies that emerge from clustering artisans do not only increase the scale of production, but also optimizes their eccentric relationships or interconnections and increase customer satisfaction as well.

\subsection{Impact of Industrial Cluster on Productivity}

One objective of the study was to find out the extent to which the wood cluster had facilitated economic growth as a result of increased productivity as compared to when the respondents' shops were dispersed in their previous locations. Seven items were used to assess the extent to which productivity has fared (Table 4). 
Table 4. Impact of Wood Industrial Cluster on Productivity.

\begin{tabular}{lllll}
\hline & Items & $\begin{array}{l}\text { Has increased/improved } \\
(\%)\end{array}$ & $\begin{array}{l}\text { Remain the same } \\
(\%)\end{array}$ & $\begin{array}{l}\text { Has decreased or worsened } \\
(\mathbf{\%})\end{array}$ \\
\hline 1. & New products development $(\mathrm{M}=2.72 ; \mathrm{SD}=0.486)$ & 74.1 & 24.1 & 1.8 \\
2. & Number of artifacts produced $(\mathrm{M}=2.93 ; \mathrm{SD}=0.274)$ & 92.9 & 6.8 & 0.3 \\
3. & Cost of production $(\mathrm{M}=2.49 ; \mathrm{SD}=0.710)$ & 62 & 25.3 & 12.7 \\
4. & Quality of products $(\mathrm{M}=2.91 ; \mathrm{SD}=0.293)$ & 90.5 & 9.5 & 0.0 \\
5. & Sales and profit margins $(\mathrm{M}=2.93 ; \mathrm{SD}=0.280)$ & 93.4 & 6 & 0.6 \\
6. & Monthly income $(\mathrm{M}=2.84 ; \mathrm{SD}=0.395)$ & 85.6 & 13.2 & 1.2 \\
7. & Number of employees $(\mathrm{M}=2.74 ; \mathrm{SD}=0.466)$ & 74.9 & 23.9 & 1.2 \\
\hline
\end{tabular}

Percentages in bold are the highest selection on an item

$\mathrm{M}=$ mean value, $\mathrm{SD}=$ standard deviation

Scale: $1=$ has decreased or worsened, $2=$ remain the same, $3=$ has increased or improved

The respondents were requested therefore to indicate whether the items or constructs have increased or improved, remained the same, decreased or worsened. The most increased or improved item reported by the respondents was sales and profit margins (93.4\%) while volumes of production $(92.9 \%)$ was the second highest item reported to have increased. Majority of the respondents (90.5\%) indicated that the quality of the products has improved. Also about $85.6 \%$ reported that monthly incomes have increased as compared to only few (1.2\%) who reported in the negative. Additionally, about three-fourth $(74.9 \%)$ of the respondents reported that there was an increase of the number of employees while about $74.1 \%$ reported that new products development has also comparatively improved. It may be important to note that, about one-fourth $(25.3 \%)$ of the respondents indicated that cost of production has remain the same while about one-eight (12.7\%) reported that the cost of production has decreased. However, surprisingly, as high as $62 \%$ of the respondents indicated that cost of production has increased as a result of being in the cluster. In general, all the items or constructs were rated above the mean value of 2 , indicating that productivity has moved beyond being the same and has increased more appreciably upon the establishment of the wood cluster compared to when the artisans were at their former locations where they operated as unclustered firms).

\subsection{Benefits of Industrial Cluster}

Industrial cluster is associated with numerous benefits, not only to the individual workers but the national economy as a whole. The respondents were therefore requested to indicate their level of agreement in relation to how they benefit from the wood cluster. Some of the benefits of the wood cluster reported by the respondents included "having a permanent site for production $(99.1 \%)$, 'sharing of technology and labour pools (96\%)' and 'splitting orders among themselves $(93.4 \%)$, and these have resulted in increase in sales $(96.6 \%)$ and export volumes $(94.3 \%)$ of made in Ghana furniture and other wood products (Table 5).

Table 5. Benefits at the Wood Cluster.

\begin{tabular}{|c|c|c|c|c|}
\hline & Item & Agree (\%) & Neutral (\%) & Disagree (\%) \\
\hline 1 & Enterprises easily get support from government, NGOs and others $(\mathrm{M}=4.00 ; \mathrm{SD}=1.29)$ & 75.5 & 8.9 & 15.6 \\
\hline 2 & Enterprises split orders among themselves $(M=4.62 ; \mathrm{SD}=0.72)$ & 93.4 & 4.3 & 2.2 \\
\hline 3 & Workshops shared the same technology and labour pool $(\mathrm{M}=4.52 ; \mathrm{SD}=0.61)$ & 96.0 & 3.1 & 0.9 \\
\hline 4 & Growth of sales and returns is high $(\mathrm{M}=4.68 ; \mathrm{SD}=0.58)$ & 96.6 & 2.6 & 0.9 \\
\hline 5 & Permanent site for production $(\mathrm{M}=4.79 ; \mathrm{SD}=0.48)$ & 99.1 & 0.3 & 0.6 \\
\hline 6 & Woodworkers fully control the market price $(\mathrm{M}=4.57 ; \mathrm{SD}=0.70)$ & 93.4 & 4.6 & 2.0 \\
\hline 7 & $\begin{array}{l}\text { Workshops learn new designs from other furniture firms that have kept them in business } \\
(\mathrm{M}=3.86 ; \mathrm{SD}=0.99)\end{array}$ & 68.9 & 23.1 & 8.1 \\
\hline 8 & $\begin{array}{l}\text { Workshops have gradually transformed from manufacturing simple wood products to high } \\
\text { quality products }(\mathrm{M}=3.82 ; \mathrm{SD}=0.96)\end{array}$ & 69.7 & 21.7 & 8.6 \\
\hline 9 & $\begin{array}{l}\text { There is an increased in export volumes of made in Ghana furniture and wood products } \\
(\mathrm{M}=4.65 ; \mathrm{SD}=0.66)\end{array}$ & 94.3 & 3.7 & 2.0 \\
\hline
\end{tabular}

Percentages in bold are the highest selection on an item,

Disagree $=$ strongly disagree plus disagree; neutral $=$ neither agree nor disagree; Agree $=$ strongly agree plus agree

$\mathrm{M}=$ mean value, $\mathrm{SD}=$ standard deviation,

Scale: $1=$ strongly disagree, $2=$ disagree, $3=$ neither agree nor disagree, $4=$ agree, $5=$ strongly agree

\subsection{Challenges of Firms in the Cluster}

The level of difficulty at the Sokoban Wood Industrial Cluster (SWIC) was assessed using a 5-point Likert scale ranging from "Not difficult at all" to "Very difficult" and consisted of nine items or constructs (Table 6). These indicators are of much importance to businesses seeking to maintain flexibility in an era of increased economic uncertainty and technological changes $[2,33]$

It is vital to note that only two of the items/constructs recorded a mean value of 3 and the rest of the items were all above the mid-point value of 3 . These two items were 
developing healthy competition among other producers at the same premises $(46.6 \%)$ and provision of direct subsidies or credits $(67.4 \%)$ which were the least items reported to be less difficult. Meanwhile, a large majority $(91.7 \%)$ of the respondents reported that finding new markets was very difficult while just a few $(2.3 \%)$ indicated that it was not difficult. In terms of availability of resources, majority $(88.5 \%)$ of the respondents indicated that access to wood, in particular as a resource was difficult possibly due to the drastic decline of most of the species in Ghana's forests especially those used for furniture production. About $81.2 \%$ reported that adding value to the resource was also difficult. Also about $87.1 \%$ of the respondents indicated that, promoting and marketing the products was difficult while only few $(5.1 \%)$ maintained that it was not difficult. Moreover, among the other items that were reported to be posing challenges toward growth and development of firms in the cluster included, introduction of new products $(84.9 \%)$, access to bank credits and loans $(84.3 \%)$ and management of waste at the wood cluster $(80.3 \%)$.

Table 6. Challenges Facing Wood and Furniture Firms in the SWIC.

\begin{tabular}{|c|c|c|c|c|}
\hline & Items & Not difficult (\%) & Neutral (\%) & Difficult (\%) \\
\hline 1. & Access to bank credit/loans $(\mathrm{M}=4.39 ; \mathrm{SD}=1.056)$ & 8 & 7.7 & 84.3 \\
\hline 2. & Provision of direct subsidies/credits $(\mathrm{M}=3.84 ; \mathrm{SD}=1.306)$ & 24 & 8.6 & 67.4 \\
\hline 3. & Access to resources, wood $(\mathrm{M}=4.32 ; \mathrm{SD}=0.846)$ & 4.4 & 7.1 & 88.5 \\
\hline 4. & Adding value to wood as a resource $(\mathrm{M}=4.03 ; \mathrm{SD}=0.927)$ & 8.1 & 10.6 & 81.2 \\
\hline 5 . & Introduction of new products $(\mathrm{M}=4.10 ; \mathrm{SD}=0.828)$ & 5 & 10.2 & 84.9 \\
\hline 6. & Finding new markets $(\mathrm{M}=4.31 ; \mathrm{SD}=0.713)$ & 2.3 & 6 & 91.7 \\
\hline 7. & Promoting and marketing the products $(\mathrm{M}=4.14 ; \mathrm{SD}=0.810)$ & 5.1 & 7.7 & 87.1 \\
\hline 8. & $\begin{array}{l}\text { Developing healthy competition among other producers at } \\
\text { the same premises }(\mathrm{M}=3.11 ; \mathrm{SD}=1.425)\end{array}$ & 42.3 & 11.1 & 46.6 \\
\hline 9. & Managing waste at the premises $(\mathrm{M}=4.14 ; \mathrm{SD}=1.342)$ & 17.4 & 2.3 & 80.3 \\
\hline
\end{tabular}

Percentages in bold are the highest selection on an item,

Note: Not difficult $=$ not difficult at all plus not difficult; Neutral = uncertain; Difficult = very difficult plus difficult;

$\mathrm{M}=$ mean value, $\mathrm{SD}=$ standard deviation,

Scale: $1=$ not difficult at all, $2=$ not difficult, $3=$ neutral, $4=$ difficult, $5=$ very difficult

\section{Discussion}

Industrial clusters are characterized as being networks of strongly interdependent firms (including specialized suppliers), knowledge producing agents (such as universities, research institutes and engineering companies), bridging institutions (like brokers and consultants) and customers, linked to each other in a value-adding production chain. This phenomenon of firms locating near one another termed agglomeration offers interactions among firms which lead to greater economic advantages such as reduced distances between buyers and sellers, common labour pool, and easier communication with suppliers, consumers and knowledge producing agents. The net effect of such clustering is economic empowerment and development of firms, cities and countries but which come with some challenges. One of such industrial clusters is the Sokoban Wood Industrial Cluster (SWIC) in Kumasi, Ghana. This study assessed the interconnections among actors, impacts, benefits and challenges in this cluster.

\subsection{Interrelationships Among Actors in the SWIC}

In this study, it was found that the SWIC consist basically of artisans $(82.3 \%)$ indicating that they appear to be the main actors while the rest are auxiliary actors who are working together to improve and expand towards meeting market demands for sustainability and growth. Meanwhile, the contribution of artisans to the development of the Small and Medium scale Furniture Enterprises (SMFEs) at the wood cluster can also be distinguished in terms of their scale, diversity and ability to support other allied industries such as the financial institutions, transport operators, porters and the food venders that otherwise have few livelihood opportunities at the SWIC. However, findings indicated that the activities of the auxiliary actors turned to be seasonal due to the fluctuations in demand and raw material availability. The suppliers (34\%) are the business merchants who provide the major raw materials resource (wood) at the cluster, and who also trade in other fittings and hardwares such as nails, castors, catches, locks, screws, abrasives, adhesives, paints, nylon robs, hand tools etc. The marketers $(20.6 \%)$ on the other hand, determine the movement and flow of domestic wood products output to the domestic market and to the global market for export. At the premises (cluster), the marketers usually welcome all potential buyers (found to be $11.4 \%$ ) who enter the cluster while publicizing the desirable attributes of products in the cluster to convince such potential buyers to make purchases. It is important to note that the buyers, though were of considerable low number, buy the wood products in large quantities from more than one producer and convey them to other parts of Ghana and also to the ECOWAS sub-regional countries. There is therefore no doubt that supportive relationships among these actors are crucial for the promotion of mutual growth and development. This is affirmed in this study by the found significant interconnections among the various actors in the SWIC and which resulted in significant $(p<0.001)$ increases in sales and profit margins. This appears affirmative of the realization of economy of scale in furniture and other wood products manufacturing through clustering and which is consistent with the findings of [34]. These authors found that social networking and geographic proximity of firms facilitate 
inter-firm cooperation in marketing activities and subsequently lead to high sales and profit levels. The results of this study also appear to confirm the finding that geographical co-location is crucial for inter-firm relationships and development of the forestry sector industries [34]. Our findings also corroborate the assertion that such firm linkages enable the firms to learn about new technologies, new markets, and changing consumer tastes, while governments and local institutions learn about industry needs, all of which enhance growth and development of the industries and national economies [35].

\subsection{Impact of Industrial Cluster on Productivity}

The finding that clustering of artisans at the SWIC has led to appreciable increase in productivity compared to when the artisans were unclustered corroborate the findings of $[36,37]$ who made similar observations in their studies. According to these authors, industrial clustering creates and exchange knowledge and skills through face-to-face interactions which lead to innovations and new products developments and which subsequently result in high productivity and sustenance of competitive advantage. This appears to be consistent with the findings in this study as presented in Table 4. It is also reported that activities in industrial clusters are much exposed to new markets through news and recommendations of the technologies by the actors which in turn entice customers [38] and subsequently leading to higher sales and profit margins. The findings in this study also appear to be consistent with [35] that dynamics of the web of healthy interrelationships that exists in a cluster is responsible for producing collective competitiveness necessary for success of firms, even in the global marketplace. It is however, important to note that congestion and some unhealthy competition in both the output and the input markets are some negative impacts of industry agglomeration [39]. On the whole, it must be noted thate there are also some interesting and divergent view that in the face of growing competition, the ability to produce highvalue products will be a source of competitive advantage and market strategy [40] for clustered industries.

Additionally, the formation of the SWIC appear to have led to more and better paying jobs which have enhanced the general economic situation of the Artisans. The overwhelming presence of the workforce engaged in the production sphere underscores the fact that labour productivity hardly decreased at the wood cluster. Since the quality and availability of human resources is a determinant of productivity, the wood cluster offers opportunities for increased productivity through the enhanced potential of human resources $(\mathrm{M}=2.74 ; \mathrm{SD}=0.466-$ Table 4$)$. This finding agrees with [41], who contends that the growth of the number of employees of a firm may reflect its ability to increasing productivity. It shows that, the SWIC is more likely to conflate ideas arising from quite different perspectives which are sometimes complementary, hence the actors have moved away from the traditional reliance on a relatively low investment mostly characterized by individualistic business processes into true collective efforts towards greater productivity and prosperity. Apparently, [42] attest that, when one firm starts a new idea, it is taken up by others and combined with suggestions of their own and it subsequently becomes the source of further new ideas and new products. And such new products development brings into reality a wide process of innovation [43].

\subsection{Benefits of Industrial Cluster}

One major and clear benefit and opportunity offered by the establishment of the SWIC is the ability of the various actors to obtain a permanent site for production which majority (99.1\% -Table 5) of the respondents indicated as their highest benefit. Besides, due to the agglomeration of the woodworkers at their current site, there is a high degree and lasting relationship and cooperation among the firms which might have made them highly interdependent. Enterprises therefore split orders, and share workshops, technologies and labour among themselves. These cordial interrelationships have provided the artisans with one strong voice on many market variables which have in turn made the woodworkers have full control over market prices of their products and subsequently led to high growth of sales and profits (as indicated by $96.6 \%$ of respondents- Table 5). The indicated benefits are reported to be characterized by high capital productivity among grouped artisans compared to ungrouped ones [44]. This situation appears to be due to the fact that the aggregation of enterprises in the wood cluster is more likely to have made transactions between firms easier and faster than what takes place in a scattered and unclustered industrial environment [35]. Additionally, the findings in this study also appear to be consistent with the report that beyond the fact that clustering of firms makes transactions faster and easier, the process reduce cost of transactions significantly compared to what is incurred in unclustered environment [35]. The ability of firms or artisans to learn new designs $(\mathrm{M}=3.86 ; \mathrm{SD}=0.99$ Table 5) from other furniture firms within the wood cluster was one of the benefits that has kept the woodworkers (artisans) in business and which is spurred by their ability to purchase new and efficient tools. Also, coupled with the consideration of customer's ideas and their culture in designing new products at the wood cluster, majority $(94.3 \%)$ of the respondents indicated that there is an increased in export volumes of made in Ghana furniture and wood products. This finding shows that, the wood cluster is more likely to exert more significant impact on the development of the wood industry and its related sub-sector as dispersed individual firms are unable to exploit internal economies of scale due to constraint on growth and expansion. Another, reason that might have been a contributing factor is that, the workers at the wood cluster may enjoy a wide base support among themselves as well as from the government and NGOs (Table 5) as they encapsulate needs from the common locality and the benefits are widely dispersed within. This leads to a more efficient and effective use of public and private resources which in turn have apparently helped to develop a strong and dynamic SWIC. 


\subsection{Challenges of Firms in the Industrial Cluster}

From the findings, new market, access to wood as raw material and adding value were the major challenges of firms in the SWIC. Also, introduction of new products, access to credit and efficient waste management are the other factors militating against the growth and development of the firms in SWIC (Table 6). All these are needed for the expected growth and development of individual firms in a cluster and the cluster as a whole and it appeared consistent with some previous study [45]. It is reported that although knowledge and innovation are fundamental catalysts for economic growth of firms, there are enough evidence to the effect that productivity within firms or industries is correlated with the monetary investments made on research and development [35] possibly aimed at accessing new markets, purchasing enough raw materials and acquiring equipment for valueadded products manufacturing. Also, the inability of the firms to maintain high environmental safety standards tends to compromise the general health and safety of all actors in the cluster. Interestingly however, [46] asserts that promoting and maintaining safe working conditions in growing industries is generally difficult but industrial players should not relent in their efforts at ensuring good working environment. The implication here is that even as it is difficult to achieve or sustain good environment in industrial clusters, much efforts need to be made to avoid compromising the health of all industrial players by putting in place some workable measures on safe health.

\section{Conclusion and Policy Implications}

This research paper provides insight into the interconnections, impacts, benefits and the challenges of an investment made by the government of Ghana in agglomerating small and medium scale furniture enterprises (SMEFEs) in an industrial cluster using Sokoban Wood Industrial Cluster (SWIC) as a case study. From the findings, the following conclusions and recommendations were made:

1. It has been established in this study that there is significantly $(p<0.001)$ greater, innate and healthy interconnection and collaboration among the actors in the SWIC and this appears to have overshadowed the perceived strong parochialism and competitive instincts that apparently characterized the former unclustered wood products business centre at Anloga and other places in Kumasi. And this has led to significant increase in sales and profit margins.

2. The establishment of the SWIC appears to be a good investment as it has had significant positive impact on productivity and growth of the furniture and wood products businesses of all actors relative to the levels at the previous unclustered wood products business centres in Kumasi.

3. The major benefits of the SWIC to the wood and furniture artisans and other actors in the industrial cluster rest in the fact that they now have a permanent site with social amenities that facilitate their business transactions at no or very minimal cost, as well as the sharing of workshop facilities, technology and labour pool all of which facilitate their operations.

4. This study has however, indicated that finding new markets, promoting and marketing products, getting access to wood as raw material, obtaining credits from banks and other financial institutions and efficient waste management are some major difficulties or challenges facing the actors in the SWIC.

5. From the results of this study and some observations made, authors recommend that much more attention should be provided to the SWIC by government agencies, non-governmental organizations (NGOs) and donor agencies and communities to enhance their potentials. This is necessary because, the furniture and wood products firms in the cluster do not only hold the potential of generating massive employment opportunities and contributing meaningfully towards helping the socio-economic development of individuals and the country at large, but they also create seedbeds to revamp other businesses for stronger industrial development.

6. Moreover, it is recommended that provision of educational facilities and a scope for enlarging the craft base through the provision of training facilities, developing a cooperative framework, provision of easy finance, constant supply of wood and uninterrupted electricity could also work to address the main challenges being encountered by artisans in the wood cluster.

\section{References}

[1] Poter M (1998). Definition of cluster industries, In: Kures M (2011). Industry clusters as an Economic Deelopment Strategy, paper presented at an information and opinionpacked meeting at Alliant Energy Centre, $27^{\text {th }}$ Sept. pp. 14.

[2] Kures M (2011). Industry clusters as an Economic Deelopment Strategy, paper presented at an information and opinion-packed meeting at Alliant Energy Centre, $27^{\text {th }}$ Sept. pp. 14.

[3] Cooke, P., and Lazzeretti, L. (2008). Creative cities, cultural clusters and local economic development, Edward Elgar, Cheltenham, UK.

[4] Sonobe, T., and Otsuka K. (2006). Cluster-Based Industrial Development: An East Asian Model. Basingstoke: Palgrave Macmillan.

[5] Albaladejo, M. (2002). Promoting SMEs in Africa: key areas for policy intervention. United Nations Development Organization, Vienna.

[6] Scott, A. J. (1988). New Industrial Spaces: Flexible Production Organisation and Regional Development in North America and Western Europe. London: Pion. 
[7] Moulaert, F., and Sekia, F. (2003). Territorial innovation models: A critical survey, Regional Studies, 37, 289-302.

[8] Karlsson, C. (2008). Handbook of research on cluster theory. UK, Cheltenham: Edward Elgar Publishing.

[9] Helmsing, A. H. J. B. (2001). Externalities, learning and governance: New perspectives on local economic development. Development and Change, 32, 277-308.

[10] UNCTAD (2002). Partnerships and Networking in Science and Technology for Development. United Nations Conference on Trade and Development, Technology for Development Series, Geneva.

[11] Piore, M. J., and Sabel, C. F. (1984). The second industrial divide: Possibilities for prosperity, New York: Basic Books Inc.

[12] Schmitz, H., and Musyck, B. (1994). Industrial districts in Europe : Policy lessons for developing countries?. World Development, 22(6), 889-910.

[13] Pseiridis, A. (2001). Clusters as an industrial strategy. University of Cambridge, UK.

[14] Dalsgaard, M. H. (2001). Danish cluster policy: Improving specific framework conditions, 347-60. Paris: OECD.

[15] Cowling, K., and Sugden, R. (1999). The wealth of localities, regions and nations: Developing multinational economies. New Political Economy, 4(3), 361-378.

[16] Bortagaray, I., and Tiffin, S. (2000). Innovation clusters in Latin America. $4^{\text {th }}$ International Conference on Technology Policy and Innovation, Curitiba, Brazil August, pp28-3.

[17] Maskell, P., and Lorenzen, M. (2004). The cluster as market organization. Urban Studies, 41(5/6), 991-1009.

[18] Lukacs, E. (2005). The economic role of SMEs in world economy especially in Europe. Journal of European Integration Studies, 4, 1.

[19] Deitz and Garcia (2000). Industry Cluster in New York State; In Walter et al. (2000). Understanding Regional Economic Growth in the New Economy: Industry Clusters, The Regional Economy. Buffalo Branch, Federal Reserve Bank of New York. pp.4.

[20] Capechi, V. (1989). The informal economy and the development of flexible specialization in Romagna. In Portes, A. and Custells, M. (Ed.). The formal economy, studies in Advance and less Development countries. London: John Hopkins University Press.

[21] Larson, A. (1991). Partner networks: Leveraging external ties to improve entrepreneurial performance. Journal of Business Venturing, 6(3), 173-88.

[22] Aryeetey, E. (2008). A Lecture Presented on the "Need for a Small and Medium Enterprise Charter in Ghana" at the Third $50^{\text {th }}$ Anniversary Lecture of the Association of Ghana Industries, June 2008 Edition.

[23] Schmitz, H. (1995). Collective Efficiency: Growth path for Small-Scale Industry. Journal of Development Studies 31(4), 529-66.

[24] Pittaway. L., Robertson M., Munir K., Denyer D., and Neely A. (2004). Networking and innovation: A systematic review of the evidence. International Journal of Management Reviews, $6,137-68$.
[25] Morris, S., Basant, R., Das, K., Ramachandarn, R., and Koshy, A. (2001). The Growth and Transformation of Small Firms in India, Oxford University Press, New Delhi.

[26] Attuquayefio, D. K and Abdulai A. (2013). Environmental and social management plan (ESMP), construction of access roads with kerbs and drains at Sokoban Wood Village, Kumasi (Draft Report), Kumasi Metropolitan Assembly (KMA). http://www.igcsp.mlgrdghanagov.com/pdf/SOKOBAN\%20W OOD\%20VILLAGE_ESMP_DRAFT\%20REPORT.pdf (Retrieved, 22/06/15)

[27] Robson, C. (2011). Real world research: A resource for users of social research methods in applied settings, $3^{\text {rd }}$ ed. John Wiley and Sons Ltd. U. K. 586pp.

[28] Cohen, L., Manion L., and Morrison, K. (2011). Research methods in education, $7^{\text {th }}$ ed., Routledge-Taylor and Francis group, London and New York. 758pp.

[29] Burgess, R. (1982). Field research: A Sourcebook and field manual. London, Routledge.

[30] Clandinin, D. J., and Connelly, F. M. (1994). Personal experience methods: California, SAGE Publications.

[31] Eriksson, P., and Kovalainen, A. (2008). Qualitative methods in business research. London: SAGE Publications.

[32] Gioia D. A., and Chittipeddi, K. (1991). Sense making and sense giving in strategic change initiation. Strategic Management Journal, 12(6), 433-448.

[33] Porter M (2000). Location, Competition, and Economic Development: Local Clusters in a Global Economy, Economic Development Quarterly, 14 (1); 15-34.

[34] Felzensztein C and Gimmon E (2008). Industrial clusters and social networking for enhancing interfirm cooperation: The case of natural resources-based industries in Chile, Journal of Business and Market, 2 (4), 187-201.

[35] Walter, B., Melson, R., Deitz, R., Garcia, R. (2000). Understanding Regional Economic Growth in the New Economy: Industry Clusters, The Regional Economy. Buffalo Branch, Federal Reserve Bank of New York. pp.4.

[36] Spender, J. C. (1998). "The Geographies of Strategic Competencies; Borrowing from Social and Educational Psychology to Sketch an Activity and a Knowledge Based Theory of the Firm" In Chandler, A. D, Hagstrom, P., and Solvell, O. eds., The Dynamic Firm. Oxford: Oxford University Press.

[37] Nonaka, I., and Takeuchi, H. (1995). Knowledge-Creating Company. Oxford: Oxford University Press.

[38] Bathelt, H. (2005b). Geographies of production: Growth regimes in spatial perspective to knowledge creation and growth in clusters. Progress in Human Geography, 29, 204216.

[39] Richardson, G. B. (2003). The organization of industry revisited. Paper presented to the DRUID Summer Conference on "Creating, sharing and transferring knowledge. The role of Institutions and Organisation". Copenhagen, June 12-14, 2003.

[40] Wu, A. (2004). Analyses on China Industry and Inverse Flow of Labor, China Industrial Economy (ZhongguoGongyeJingji), 2004 (12). 
[41] Camagni, R. P. (1995). The concept of innovative milieu and its relevance for public polices in European lagging regions. Papers in Regional Science, 74, 317-340.

[42] Feldman, M. P. (1999). The new Economics of innovation, spillovers and agglomeration: A review of empirical studies. Economics of Innovation and New Technology, 8, 5-25.

[43] Best, M. H. (1990). The New Competition: Institutions for industrial restructuring. Polity Press, Cambridge and Oxford.

[44] Bair, J., and Gereffi, G. (2003). Upgrading uneven development and jobs in the North American apparel industry. Global Networks, 3(2), 147-169.
[45] Walter, B., Melson, R., Deitz, R., Garcia, R. (2000). Understanding Regional Economic Growth in the New Economy: Industry Clusters, The Regional Economy. Buffalo Branch, Federal Reserve Bank of New York. pp.4.

[46] Townson, I. M. (1995). Incomes from non-timber forest products: Patterns of enterprise activity in the forest zone of southern Ghana. The main Report, Oxford University, UK. 